\title{
KOMPETENSI BARISTA DALAM MENYAMPAIKAN EXPERIENTIAL MARKETING DI COFFEE SHOP DI KOTA BANDUNG
}

\section{BARISTA'S COMPETENCY IN DELIVERING EXPERIENTIAL MARKETING IN COFFEE SHOP IN BANDUNG CITY}

\author{
Ahmad Alvarizy*, Yosini Deliana \\ Program Studi Agribisnis, Fakultas Pertanian, Universitas Padjadjaran \\ Jl. Raya Jatinangor Sumedang Km. 21 \\ *E-mail: ahmad.alvarizy8@gmail.com \\ (Diterima 01-05-2021; Disetujui 03-06-2021)
}

\begin{abstract}
ABSTRAK
Masyarakat saat ini sudah menjadikan minum kopi di kedai atau warung kopi sebagai budaya baru. Banyak orang yang berminat terjun di bidang usaha kopi karena potensi pasar yang sangat ingin mengeksplorasi proses penyeduhan dan ingin berbagi dengan orang di sekelilingnya. Salah satu penentu sukses bisnis coffee shop adalah keberadaan barista. Barista adalah sebutan untuk seseorang yang pekerjaannya membuat dan menyajikan kopi kepada pelanggan. Maka dari itu, barista harus memiliki kompetensi dalam menyampaikan experiential marketing seperti memperlakukan pelanggan sebagai seorang teman, mengingat nama pelanggan, dan selalu tersenyum, dan barista pun harus memiliki kompetensi sesuai dengan peraturan dari Kementerian Ketenagakerjaan dan Trasnmigrasi. Tujuan penelitian ini tidak lain adalah mengetahui tingkat kompetensi barista dalam menyampaikan nilai-nilai pada experiential marketing dan mengetahui tingkat kompetensi barista menurut SKKNI No. 370 tahun 2013. Penelitian ini dilakukan dengan menggunakan kuesioner kepada barista dengan teknik kuantitatif dan melakukan wawancara dengan para informan. Hasil dari penelitian ini menunjukan bahwa mayoritas barista sudah kompeten pengaplikasian aspek dari experential marketing ini. Berdasarkan pengukuran kompetensi barista menurut SKKNI Barista dapat disimpulkan bahwa mayoritas barista sudah sangat mampu untuk memenuhi standar walaupun mayoritas barita tidak mengetahui standar tersebut, dan juga hanya sebagian kecil dari barista yang menjadi responden yang telah mengikuti Sekolah Barista.
\end{abstract}

Kata Kunci: Kompetensi, Barista, Experiential Marketing, SKKNI, Coffee Shop

\begin{abstract}
People have now made drinking coffee in coffee shops a new culture. Many people who are interested in getting into the coffee business because of the market potential are eager to explore the brewing process and want to share with those around them. One of the determinants of a coffee shop business success is the presence of a barista. Barista is the name for someone whose job is to make and serve coffee to customers. Therefore, baristas must have competence in delivering Experiential marketing such as treating customers as friends, remembering customers' names, and always smiling and baristas must have competence in accordance with the regulations of the Ministry of Manpower and Transmigration. The purpose of this research is none other than knowing the level of competence of baristas in conveying the values of experimental marketing and knowing the level of competence of baristas according to SKKNI No. 370 of 2013. This research was conducted using a questionnaire to baristas with quantitative techniques and conducting interviews with informants. The results of this study indicate that the majority of baristas are competent in applying this aspect of Experiential marketing. Based on the measurement of barista competence according to SKKNI Barista, it can be concluded that the majority of baristas are very capable of meeting the standards even though the majority of baristas do not know these standards and also only a small proportion of baristas who are respondents have attended Barista Schools.
\end{abstract}

Keywords: Competence, Barista, Experiential Marketing, SKKNI, Coffee Shop 


\section{KOMPETENSI BARISTA DALAM MENYAMPAIKAN EXPERIENTIAL MARKETING \\ DI COFFEE SHOP DI KOTA BANDUNG \\ Ahmad Alvarizy, Yosini Deliana}

\section{PENDAHULUAN}

Dewasa ini sangat banyak orang yang berminat terjun di bidang usaha kopi karena potensi pasar yang sangat menjanjikan. Solikatun et al (2015) menyatakan bahwa masyarakat saat ini sudah menjadikan minum kopi di kedai atau warung kopi sebagai budaya baru. gaya hidup baru anak muda masa kini yaitu mengunjungi coffee shop secara berkala khususnya di kota metropolitan seperti di Jakarta dan Bandung (Herlyana, 2012).

Bisnis coffee shop semakin banyak diminati para pelaku bisnis. Fenomena ini dapat dilihat dengan sangat banyak menjamur usaha coffee shop di kota-kota besar di Indonesia tak terkecuali di Kota Bandung. Pesatnya pertumbuhan coffee shop di Kota Bandung dapat dilihat pada Tabel 1.

Tabel 1. Data jumlah coffee shop Kota Bandung

\begin{tabular}{ccc}
\hline Tahun & Jumlah (Gerai) & Pertumbuhan (\%) \\
\hline 2016 & 116 & 20 \\
2017 & 139 & 13 \\
2018 & 157 & $15^{*}$ \\
2019 & 181 & \\
*proyeksi & \\
Sumber: Dinas Kebudayaan dan Pariwisata Kota \\
\multicolumn{3}{c}{ Bandung 2019 }
\end{tabular}

Industri coffee shop termasuk subsektor industri kreatif kuliner. Di Kota Bandung subsektor fashion, kuliner dan kerajinan merupakan tiga industri dominan yang berkontribusi besar untuk
PDB, dan industri fashion berkontribusi $39,24 \%$, kerajinan berkontribusi $26,52 \%$, sementara kuliner berkontribusi sebesar $11.86 \%$ dengan nilai tidak kurang dari $\mathrm{Rp}$ 215 miliar (Disbudpar Bandung 2018), cafe adalah usaha yang dominan dalam jumlah, dan coffee shop adalah salah satu jenis cafe selain Buffet, Urban Foodcourt, Bistro, dan Brasserie.

Sejalan dengan bisnis coffee shop dimana banyak orang yang berkumpul dan berinteraksi, maka pemasaran pengalaman (Experiential marketing) dapat diterapkan dalam usaha coffee shop. Barista memiliki peranan yang sentral di coffee shop, maka barista juga merupakan faktor komponen kunci untuk menyampaikan nilai-nilai experiential marketing. Liu dan Gui (2017) menyatakan bahwa experiential marketing yang harus dilakukan barista, yaitu memperlakukan pelanggan sebagai seorang teman, mengingat nama pelanggan, dan selalu tersenyum. Schmitt (2010) menyatakan bahwa experiential marketing adalah metode pemasaran yang memandang konsumen sebagai manusia yang rasional dan emosional yang peduli untuk mencapai pengalaman yang menyenangkan. Terdapat lima pengalaman pada experiential marketing atau biasa disebut strategic experiential 
modules (SEMs), yaitu pengalaman indrawi (sense), pengalaman afektif (feel), pengalaman kognitif kreatif (think), pengalaman fisik, perilaku dan gaya hidup (act), dan pengalaman identitas sosial yang dihasilkan dari yang berkaitan dengan kelompok referensi atau budaya (relate).

Salah satu penentu sukses bisnis coffee shop adalah keberadaan barista. Barista adalah orang yang bertugas menyeduh kopi dan mengerti dalam eksekusinya (Panggabean, 2012). Selain menyeduh kopi, mereka pun berinteraksi dengan para pelanggan mulai dari membahas kopi yang dipesan hingga permasalahan pribadi. Barista adalah profesi kunci dalam menciptakan keunggulan sebuah coffee shop, karenanya kemampuan barista terhadap profesinya sangat mempengaruhi kinerjanya, yang pada gilirannya akan menentukan kualitas seduhan kopi dan penawaran coffee shop secara keseluruhan kepada konsumen.

Kemampuan dasar barista sudah diatur oleh Kementerian Tenaga Kerja dan Transmigrasi RI No. 370 tahun 2013 berupa Standar Kompetensi Kerja Nasional Indonesia (SKKNI). Kemampuan dasar barista menurut SKKNI yaitu mengelola bahan baku penunjang kegiatan sebagai barista, mengelola peralatan dan perlengkapan penunjang kegiatan barista, mengelola area kerja, menangani pelanggan yang berkunjung, mengoperasikan peralatan penunjang kegiatan barista, mengembangkan produk minuman kopi, mengikuti prosedur kesehatan, keselamatan dan keamanan di tempat kerja, menangani situasi konflik, dan dapat berkomunikasi lisan dalam berbahasa Inggris pada tingkat operasional dasar.

Tujuan dari penelitian ini adalah untuk memperoleh tingkat kompetensi barista dalam menyampaikan nilai-nilai pada eksperiental marketing dan memperoleh tingkat kompetensi barista menurut SKKNI No. 370 tahun 2013.

\section{METODE PENELITIAN}

Metode penelitian yang digunakan berupa metode kuantitatif deskriptif. Penelitian ini dilaksanakan di coffee shop kota Bandung dengan waktu pelaksanakaan sepanjang bulan November 2020. Variabel yang diteliti adalah tingkat kemampuan barista dalam menyampaikan experential marketing dan tingkat kemampuan dalam menjalankan standar kompetensi barista yang telah dimuat pada SKKNI No. 370 
tahun 2013 yang nantinya dikemas dalam bentuk kuesioner dengan menentukan tingkat kemamupuan menggunakan skala likert.

Populasi pada penelitian ini tidak diketahui jumlahnya, maka sampel yang akan digunakan berjumlah lebih dari 30 atau kurang dari 500 sampel (Alwi, 2015). Responden didapat dengan menggunakan random sampling dalam penentuan coffee shop tempat barista bekerja dan volunteer respond oleh barista untuk menjadi responden untuk mengisi kuesioner pada penelitian ini.

Rancangan analisis data pada menelitian ini menggunakan distribusi frekuensi. Data yang telah terkumpul akan dihitung rata-rata, kemudian dicocokan dengan tabel distribusi frekuensi. Tabel distribusi frekuensi didapat dengan menghitung panjang kelas dan lebar kelas dengan hasil sebagai berikut yang ditunjukan oleh Tabel 2.

Tabel 2. Acuan Kategori Indeks dan Interval Nilai Responden

\begin{tabular}{clr}
\hline No & \multicolumn{1}{c}{ Kategori } & \multicolumn{1}{c}{ Interval Nilai } \\
\hline 1 & Sangat Rendah & $1-1,7$ \\
2 & Rendah & $1,8-2,5$ \\
3 & Sedang & $2,6-3,3$ \\
4 & Tinggi & $3,4-4,1$ \\
5 & Sangat Tinggi & $4,2-5$ \\
\hline
\end{tabular}

\section{HASIL DAN PEMBAHASAN}

Penelitian ini akan berfokus pada kompetensi barista dalam menyampaikan eksperential marketing. Responden yang didapat pada penelitian berjumlah 50 orang barista dari berbagai macam coffee shop.

Tabel 3. Jenis Kelamin \& Usia

\begin{tabular}{clc}
\hline No & \multicolumn{1}{c}{ Kategori } & Frekuensi \\
\hline 1 & Laki-laki & 45 \\
2 & Perempuan & 5 \\
\hline & Jumlah & 50 \\
\hline No & Kategori & Frekuensi \\
\hline 1 & $<25$ tahun & 37 \\
2 & $25-40$ tahun & 12 \\
3 & $40-55$ tahun & 1 \\
4 & $>55$ tahun & 0 \\
\hline & Jumlah & 50 \\
\hline
\end{tabular}

Sumber: Analisis Data Primer (2020)

Profesi barista ini didominasi oleh jenis kelamin laki-laki sebanyak 45 barista (Tabel 3). Barista didominasi oleh laki-laki karena terdapat kecenderungan jam kerja hingga larut malam dan tingkat kesukaan yang lebih terhadap kopi. Usia barista pun didominasi pada rentang umur kurang dari 25 tahun. Selain memang merupakan umur produktif, profesi barista ini pun dapat digolongkan sebagai profesi baru yang mana tidak terdapatnya barista yang berusia lebih dari 55 tahun.

\begin{tabular}{ccc}
\multicolumn{3}{l}{ Tabel 4. } \\
\hline No & Kategori & Frekuensi \\
\hline 1 & $<1$ tahun & 8 \\
2 & $1-2$ tahun & 19 \\
3 & $2-3$ tahun & 10 \\
4 & $3-4$ tahun & 8 \\
5 & $>4$ tahun & 5 \\
\hline & Jumlah & 50 \\
\hline
\end{tabular}

Sumber: Analisis Data Primer (2020) 
Dilihat dari Tabel 4 juga dapat diamati bahwa baritsa yang saat ini bekerja didiominasi oleh barista yang telah bekerja 1-3 tahun ke belakang sebanyak $64 \%$ barista. Mereka mulai bergabung menjadi barista mulai tahun 2017 dan meningkat pada tahun 20182019. Sangat sedikit masyarakat yang menjadi barista pada satu tahun terakhir karena terjadi pandemi virus corona pada tahun 2020 yang menyebabkan sangat sedikitnya lowongan barista.

Tabel 5. Sumber Pengetahuan Barista

\begin{tabular}{ccc}
\hline No & Kategori & Frekuensi \\
\hline 1 & $<1$ tahun & 8 \\
2 & $1-2$ tahun & 22 \\
3 & $2-3$ tahun & 24 \\
4 & $3-4$ tahun & 28 \\
\hline
\end{tabular}

Sumber: Analisis Data Primer (2020)

Sebelum seseorang bisa menjadi barista, mereka harus belajar terlebih dahulu. Terdapat beberapa sumber pengetahuan barista yang bisa didapat beberapa diantaranya seperti Sekolah Barista, Mentor Barista, teman, atau pun otodidak. Pertanyaan pada Tabel 5 dijawab oleh responden dengan boleh memilih lebih dari satu pilihan. Hasil dari data tesebut menunjukan bahwa mayoritas barista mendapat ilmu barista selain dari sekolah barista dan hanya 8 orang saja yang mengikuti sekolah barista. Barista merasa untuk mengikuti kelas barista ini membutuhkan dana yang tidak sedikit. Sekolah barista yang sudah credible yang salah satunya ada di Kota Bandung yaitu, 5758 Coffee Lab dengan kebutuhan dana sebesar Rp3.500.000,00.

Experiential marketing merukan hal yang penting untuk diaplikasikan dalam pemasaran coffee shop. Eksperiental marketing adalah proses mengidentifikasi dan memuaskan kebutuhan pelanggan dan aspirasi secara menguntungkan, melibatkan mereka melalui komunikasi dua arah yang akan membuat kepribadian sebuah brand menjadi hidup dan menambah nilai bagi pelanggan sesuai yang ditargetkan (Smilansky, 2009). Metode ini akan sangat membantu untuk menciptakan pengalaman dan emosional kepada pelanggan.

Respon barista mengenai kemampuan dalam menyampaikan exprential marketing berdasarkan teori yang dikemukakan Schmitt (2010) akan dijelaskan pada Tabel 6.

Setelah mengamati Tabel 6 dapat ditarik beberapa analisis. Barista dapat diartikan sudah mampu untuk menyampaikan pengalaman secara indrawi (sense), antara lain seperti menyesuaikan posisi tata letak ruang agar pengunjung nyaman, memutar musik yang tepat, dan memberikan sajian yang memuaskan. 


\section{KOMPETENSI BARISTA DALAM MENYAMPAIKAN EXPERIENTIAL MARKETING \\ DI COFFEE SHOP DI KOTA BANDUNG}

Ahmad Alvarizy, Yosini Deliana

Tabel 6. Tingkat Kemampuan Experential Marketing Barista

\begin{tabular}{|c|c|c|c|}
\hline Dimensi & Indikator & Nilai & $\begin{array}{l}\text { Kategori } \\
\text { Indeks }\end{array}$ \\
\hline \multirow{5}{*}{ Sense } & Kenyamanan & 4,34 & Sangat \\
\hline & Ruang & & Tinggi \\
\hline & Mengatur Musik & 4,18 & Tinggi \\
\hline & Sajian & 4,16 & Tinggi \\
\hline & Memuaskan & & \\
\hline \multirow{6}{*}{ Feel } & Pelanggan & 4,34 & Sangat \\
\hline & sebagai Teman & & Tinggi \\
\hline & Mengingat & 3,70 & Tinggi \\
\hline & Nama & & \\
\hline & Tersenyum & 4,60 & Sangat \\
\hline & & & Tinggi \\
\hline \multirow{5}{*}{ Think } & Menjelaskan & 4,60 & Sangat \\
\hline & Produk & & Tinggi \\
\hline & Menjelaskan & 4,32 & Sangat \\
\hline & Teknik & & Tinggi \\
\hline & Penyeduhan & & \\
\hline \multirow{3}{*}{ Act } & Menyampaikan & 3,80 & Tinggi \\
\hline & Sebuah Konsep & & \\
\hline & Perilaku & & \\
\hline \multirow{3}{*}{ Relate } & Menyampaikan & 3,84 & Tinggi \\
\hline & Pesan-Pesan & & \\
\hline & $\begin{array}{l}\text { yang } \\
\text { Disuarakan }\end{array}$ & & \\
\hline
\end{tabular}

Sumber: Analisis Data Primer (2020)

Liu dan Gui (2017) menyatakan bahwa experiential marketing yang harus dilakukan barista, yaitu memperlakukan pelanggan sebagai seorang teman, mengingat nama pelanggan, dan selalu tersenyum. Kegiatan tersebut akan memberikan pengalaman afektif (feel) yang membuat pelanggan merasa nyaman dan diakui keberadaannya. Pada Tabel 6 dapat dilihat bahwa barista sudah mampu menyampaikan nilai nilai pengalaman afektif tersebut.

Selain memberikan pengalaman secara emosional, barista pun harus mampu untuk memberikan pengalaman berupa muatan pengetahuan kognitif kreatif (think). Experiential marketing yang harus diberikan barista kepada pelanggan adalah pengalaman kognitif kreatif (think) seperti menjelaskan produk yang dijual oleh coffee shop dan teknik penenyuhan apa yang dipesan oleh pelanggan. Pada hal ini Barista sudah tergolong sangat mampu untuk mengaplikasikannya.

Barista harus pula mampu untuk menciptakan pengalaman fisik dan perilaku gaya hidup (act) seperti membuat sebuah gerakan gaya hidup baru seperti memberikan pengalaman jika anda berada di coffee shop ini anda akan berperilaku seperti orang tahun 70-an. Setelah melihat Tabel 6 bahwa kecenderungan barista menyatakan dirinya sudah mampu.

Terakhir adalah pengalaman identitas sosial yang dihasilkan dari yang berkaitan dengan kelompok referensi atau budaya (relate). Barista harus bisa menyampaikan keunikan kampanye yang terkesan positif bagi para pelanggan seperti "go-Green" atau menyatakan bahwa "setiap kopi yang anda beli akan berkontribusi kepada petani kopi Indonesia". Dari data pada Tabel 3 bahwa kemampuan barista pada poin ini cenderung mampu dengan nilai rata-rata sebesar 3,84 . 
Rasmikayati et al (2017) yang telah melakukan pengamatan mengenai sikap dan perilaku konsumen dalam pembelian kopi dengan hasil bahwa mayoritas orang berkunjung ke coffee shop karena suasana yang nyaman.

Yulianti \& Deliana (2018) juga telah melakukan pengamatan mengenai gaya hidup kaitannya dengan keputusan konsumen dalam membeli minuman kopi dengan dengan hasil bahwa gaya hidup memiliki korelasi yang kuat menuju sangat kuat dengan keputusan pembelian konsumen dan memiliki pengaruh yang positif dan searah.

Selanjutnya bagian ini akan menganalsis dasar kompetensi barista menurut Menurut UU Republik Indonesia No. 13 tahun 2003 tentang Standar Kompetensi Kerja Nasional Indonesia Barista yang diatur oleh Kementrian Tenaga Kerja dan Transmigrasi RI tahun 2013.

Tabel 7. Barista Mengetahui SKKNI Barista

\begin{tabular}{clc}
\hline No & \multicolumn{1}{c}{ Kategori } & Persentase (\%) \\
\hline 1 & Tahu & 34 \\
2 & Tidak Tahu & 66 \\
\hline Jumlah & 100 \\
\hline \multicolumn{2}{l}{ Sumber: Analisis Data Primer } & $(2020)$
\end{tabular}

Sebelum berbicara lebih lanjut mengenai kompetensi barista menurut SKKNI barista, Tabel 7 menunjukan bahwa mayoritas barista (66\%) tidak mengetahui SKKNI Barista. Barista yang mengetahui SKKNI Barista ini didapat dari pelatihan sebelum bekerja yang dilakukan oleh coffee shop tempat mereka bekerja atau sharing antar barista yang membuat mereka menjadi tahu. Barista yang mengetahui SKKNI Barista ini hanya sebanyak 34\%.

Tabel 8. Tingkat Kemampuan berdasarkan

\begin{tabular}{|c|c|c|c|}
\hline $\begin{array}{l}\text { Kemam- } \\
\text { puan }\end{array}$ & Indikator & Nilai & $\begin{array}{c}\text { Kategori } \\
\text { Indeks }\end{array}$ \\
\hline \multirow{3}{*}{$\begin{array}{l}\text { Peren- } \\
\text { canaan }\end{array}$} & Mengelola Bahan & 4,50 & Sangat \\
\hline & Mengelola & 4.50 & $\begin{array}{l}\text { 1inggi } \\
\text { Sangat }\end{array}$ \\
\hline & Peralatan & & Tinggi \\
\hline \multirow{2}{*}{$\begin{array}{l}\text { Persi- } \\
\text { apan }\end{array}$} & Mempersiapkan & 4,66 & Sangat \\
\hline & Area Kerja & & Tinggi \\
\hline \multirow{6}{*}{$\begin{array}{l}\text { Pelak- } \\
\text { sanaan }\end{array}$} & Menangani & 4,64 & Sangat \\
\hline & Pelanggan & & Tinggi \\
\hline & Mengoperasikan & 4,62 & Sangat \\
\hline & Alat & & Tinggi \\
\hline & Mengembangkan & 4,26 & Sangat \\
\hline & Produk Kopi & & Tinggi \\
\hline \multirow{5}{*}{$\begin{array}{c}\text { Penge- } \\
\text { lolaan } \\
\text { SDM }\end{array}$} & Mengikuti K3 & 4,56 & Sangat \\
\hline & & & Tinggi \\
\hline & Menangani & 4,36 & Sangat \\
\hline & Konflik & & Tinggi \\
\hline & Berbahasa Inggis & 3,58 & Tinggi \\
\hline
\end{tabular}

Sumber: Analisis Data Primer (2020)

Sebelum barista memulai bekerja, meraka harus tahu apa saja yang harus dipersiapkan seperti mengelola bahan baku dan mempersiapkan peralatan dan perlengapan. Mengelola bahan baku di sini meliputi mengatur jumlah kebutuhan bahan dan mempersiapkan peralatan seperti kalibrasi alat. Pada Tabel 8 terlihat barista sudah sangat mampu.

Selanjutnya barista harus bisa mempersiapkan, menata, dan mengatur area kerja (cafe bar). Tujuan dari poin ini adalah agar barista dapat bekerja dengan 


\section{KOMPETENSI BARISTA DALAM MENYAMPAIKAN EXPERIENTIAL MARKETING \\ DI COFFEE SHOP DI KOTA BANDUNG \\ Ahmad Alvarizy, Yosini Deliana}

nyaman dengan menata peralatan dan perlengkapan seperti grinder, mesin espresso, dan lain-lain dengan baik dan benar. Dalam hal ini barista sudah sangat mampu untuk menjalankannya.

Kegiatan utama barista pada saat berada di bar adalah menangani pengunjung, mengolah produk kopi, dan mengoperasikan alat penunjuang untuk mengolah produk kopi. Barista memang sudah semestinya paham dalam hal ini, dan terbukti pada Tabel 8 bahwa barista sudah sangat mampu dalam mengaplikasian poin tersebut.

Terakhir adalah mengelolaan sumber daya yang dimana barista mengikuti prosedur dasar kerja umum seperti mengikuti prosedur K3, menangani situasi konfilk, dan dapat berbahasa inggris. Dilihat pada Tabel 8 bahwa nilai yang diperoleh sudah sangat tinggi, namun memang pada pengaplikasian bahasa Inggris masih lebih kecil diantara yang lain.

\section{KESIMPULAN DAN SARAN}

Tingkat kompetensi barista dalam menyampaikan nilai-nilai pada eksperiental marketing pada coffee shop Kota Bandung adalah tinggi. Mereka mampu menyampaikan seluruh aspek experential maketing seperti pandai mengatur coffee shop agar pengunjung memiliki rasa nyaman saat berkunjung, kemudian mahir dalam berinteraksi dengan pelanggan yang nantinya akan membuat mereka merasa diakui dan memiliki ikatan emosional dengan barista. Selanjutnya, barista juga memiliki daya pengetahuan tentang komoditas kopi yang menarik untuk nantinya dibagikan kepada pelanggan. Barista pula akan memberikan kesan yang tepat sesuai dengan konsep coffee shop tempat mereka bekerja agar pengalaman yang pengunjung dapatkan tidak akan terlupakan. Terakhir adalah barista ini pula akan menyampaikan campign yang dilakukan coffee shop yang nantinya akan memberikan kesan setuju dan mendukung campign tersebut. Akan tetapi, ada beberapa barista yang masih belum begitu maksimal dalam menyampaikan experiential marketing ini.

Tingkat kompetensi barista menurut SKKNI No. 370 tahun 2013 pada barista coffee shop Kota Bandung adalah sangat tinggi. Walaupun hanya sebagian kecil barita yang tahu mengenai SKKNI Barista ini, akan tetapi mereka sudah memenuhi standar dari peraturan tersebut. Barista ini sudah mampu dan paham bagaimana cara merencanakan, 
mempersiapkan, dan melaksanakan semua kegiatan standar dasar barista sesuai ketentuan coffee shop tempat mereka bekerja masing-masing. Mengenai sumber pengetahuan barista, hanya terdapat 8 orang saja yang telah mengikuti Sekolah Barista, namun pada kenyataannya hampir semua barista mampu mengkuti SKKNI Barista

Adapun saran pertama kepada Barista diharapkan lebih memahami mengenai konsep experiential marketing karena nantinya akan menunjang pemasaran yang dibawakan oleh pengelola coffee shop. Kedua, kepada pihak pengelola coffee shop melakukan dan memberikan informsi kepada barista mengenai konsep pengalaman fisik, perilaku, gaya hidup, dan gerakan kampanye yang diterapkan oleh coffee shop. Karena barista dalam coffee shop dapat berperan sebagai penyampai aspekaspek eksperential marketing. Ketiga adalah diadakannya sosialisasi kepada barista mengenai SKKNI bagi pihak pemerintah khususnya Kementerian Ketenagakerjaan dan Trasmigrasi dan pada pihak penyelenggara Sekolah Sertifikasi Barista agar barista ini mengetahui dasar-dasar kompetensi sebelum menjalankan profesinya.

\section{DAFTAR PUSTAKA}

Agoes Patub B. N. (2011). Modul Seminar "Peran Komunitas Musik Etnik dalam Kebangkitan Budaya Bangsa. Yogyakarta: Komunitas Suling Bambu Nusantara.

Agung, I Gusti Ngurah. (2006). Statistika Penerapan Model Rerata Sel Multivariat dan Model Ekonometri dengan SPSS. Jakarta: Yayasan SAD Satria Bhakti.

Anisailah, R. (2017). Analisis Kualitas Produk dan Pelayanan Barista di Krema Koffe Pekanbaru. 4(1), 116.

Aswar S. 2011. Sikap Manusia: Teori dan Pengukuran. Jakarta: Pustaka Pelajar

Basu Swasta. (1993). Pengantar Bisnis Modern. Cetakan ketiga. Yogyakarta: Liberty.

Biref, A. \& Robeson, L. (2017). Job Attitude Organization: An Exploratory Study. Journal of Applied Social Psychology, 19(9), 717-727.

Easto, Jessica. (2017). Craft Coffee: A Manual. Chicago: Agate Publising

Fibrianto, K., Putri, M., \& Daya, A. (2018). Effect of Particle Size Variation and Brewing Method of Coffee on Multisensory Perception: Literature Review. 6(1), 12-16.

Hasan, M. Iqbal. (2001). Pokok-pokok Materi Statistik I (Statistik Deskriptif), Jakarta: Bumi Aksara. Herlyana, E. (2012). Fenomena Coffee Shop Sebagai Gejala Gaya Hidup Baru Kaum Muda. 13(1), 188-204. Hutasoit, R. A., Solikhun, S., \& Wanto, A. (2018). Analisa Pemilihan 
Barista Dengan Menggunakan

Metode Topsis (Studi Kasus: Mo

Coffee). KOMIK (Konferensi

Nasional Teknologi Informasi Dan

Komputer), 2(1), 256-262.

Illy, Andrea \& Viani, Rinantonio. (2005).

Espresso Coffee: The Science of

Quality $2^{\text {nd }}$ Edition. Italy: Elsevier

Idrus Alwi (2015). Jurnal Ilmiah

Pendidikan MIPA: Kriteria

Empirik dalam Menentukan

Ukuran Sampel Pada Pengujian

Hipotesis Statistika dan Analisis

Butir. 2(2), 140-148.

John W.Creswell. (2014). Research

Design: Qualitative, Quantitative, and Mixed Methods Approaches.

London: SAGE Publications Ltd.

Kementerian Ketenagakerjaan dan

Trasnmigrasi Republik Indonesia.

2003. Undang-undang No. 13

Tahun $2003 \quad$ Tentang

Ketenagakerjaan. Sekretariat

Negara. Jakarta.

Kementerian Ketenagakerjaan dan

Trasnmigrasi Republik Indonesia.

(2013). Keputusan Kementerian

Tenaga Kerja dan Trasnmigrasi

Republik Indonesia No. 370 Tahun

2013 tentang Penetapan Standar

Kompetensi Kerja Nasional

Indonesia Kategori Penyediaan

Makanan dan Minuman Golongan

Penyediaan Makanan dan Minuman

Sub Golongan Bar Kelompok

Usaha Rumah Minum/Kafe.

Kementerian Tenaga Kerja dan

Trasnmigrasi. Jakarta.

Kementerian Pendidikan dan

Kebudayaan RI. (2011). Kerangka

Kualifikasi Nasional Indonesia.

Jakarta.
Kotler, Philip \& Armstrong, Gary. (2008). Prinsip-prinsip Pemasaran. Jakarta: Penerbit Erlangga.

Liu, Yajuan \& Gui, Ping. (2017). Advances in Computer Science Research (ACSR): An Analysis of the Problems and Countermeasures in the Application of Experiential Marketing - A Case Study of Starbucks, 2, 378-382.

Panggabean, E. (2012). The secret of barista: rahasia meracik kopi ala barista profesional. Jakarta: Wahyu Media.

Rasmikayati, Elly et.al. (2017). Jurnal Pemikiran Masyarakat Ilmiah Berwawasan Agribisnis: Kajian Sikap Dan Perilaku Konsumen Dalam Pembelian Kopi Serta Pendapatnya Terhadap Varian Produk Dan Potensi Kedainya, 3(2): 117-133.

Peppers, Don \& Rogers, Martha. (2017). Managing Customer Experience and Relationship: A Strategic Framework. New Jersey: John Wiley \& Sons.

Prihandini, O. D., \& Handoyo, P. (2014). Pola Interaksi Simbolik Barista. Paradigma, 2(2), 1-8.

Reitz, J. K. (2015). Espresso. Food, Culture \& Society, 10(1), 8.

Sartika, Ghia \& Deliana, Yosini. (2020). Esearch Journal of Agriculture and Forestry Sciences: Market segmentation of Roasted Bean. $8(1), 1-8$.

Sarwono, Jonathan. (2015). Rumusrumus Populer dalam SPSS 22 untuk Riset Skripsi. Yogyakarta: CV. Andi Offset. 
Schmitt, Bernd (2010): Experiential Marketing: Journal of Marketing Management, 15:1-3, 53-67

Smith, Travis J. (2015). Understanding the Millennial Generation: Journal of Business Diversity, 15(1), 39-47

Silalahi, Ulber. (2015). Metode Penelitian Sosial Kuantitatif. Bandung: Refika Aditama.

Smilansky, S. (2009). Experiential Marketing: A Practi- cal Guide to Interactive Brand Experiences. London: Kogan Page.

Solikatun, S., Kartono, D. T., \& Demartoto, A. (2015). Perilaku Konsumsi Kopi Sebagai Budaya Masyarakat Konsumsi (Studi Fenomenologi Pada Peminum Kopi Di Kedai Kopi Kota Semarang): Jurnal Analisa Sosiologi, 4(1), 6074.
Sukandarrumidi. (2002). Metode Penelitian. Yogyakarta : Gadjah Mada University Press.

Verma, Dheeraj \& Verma, Devendra S. (2013). International Journal of Science and Research (IJSR): Customer Relationship Management Practices In Selected Organized Retail Outlets: A Case Study of Indore City, 2(4), 358-365

You-Ming, C. (2010). Study on the Impacts of Experien- tial Marketing and Customers' Satisfaction Based on Relationship Quality, International Journal of Organizational Innovation 3(1): 189209.

Yulianti, Yanti \& Deliana, Yosini. (2018). Jurnal Agrisep: Correlation of Lifestyle with Consumer Decision on Buying Coffee 17(1): 39-50. 